\section{0 aspecto contextual da textualidade via LSF numa intervenção pedagógica sobre a atividade tradutória}

The contextual aspect of textuality via SFL in a pedagogical intervention on translation

Teresinha Penaforte VIEIRA (UECE)

terevieira2013@gmail.com

Pedro Henrique Lima PRAXEDES FILHO (UECE) pedro.praxedes@uece.br

Recebido em: 30 de out. de 2019. Aceito em: 05 de maio de 2020.
VIEIRA, Teresinha Penaforte; PRAXEDES FILHO, Pedro Henrique

Lima. O aspecto contextual da

textualidade via LSF numa intervenção pedagógica sobre a atividade tradutória. Entrepalavras, Fortaleza, v. 10 , n. esp., p. $8-28$, jul. 2020. DOI: 10.22168/2237-6321-9esp1759.

Resumo: Neste artigo, buscamos relatar parte de uma pesquisa cujo objetivo foi investigar o desenvolvimento da subcompetência bilíngue e metarreflexão de tradutores em formação (HURTADO ALBIR, 2005; PACTE, 2003; VASCONCELLOS; PAGANO, 2005; entre outros) sobre aspectos relativos à textualidade/tessitura (HALLIDAY; MATTHIESSEN, 2014), no par linguístico português-inglês. A parte relatada trata apenas do aspecto 'relação textos-contexto'. A pesquisa, orientada pela LSF e estudos da tradução, foi desenvolvida via intervenção pedagógica aplicada a bacharelandos em Língua Inglesa/Tradução da Universidade Estadual do Ceará. O corpus foi constituído pelas respostas a questões em cinco atividades pedagógicas e pelos comentários feitos em entrevistas inicial e final. Os resultados relativos à Atividade 1, sobre a relação textos-contexto, e a comentários na entrevista final demonstraram uma elevação no nível de subcompetência bilíngue dos participantes e de sua capacidade metarreflexiva sobre esse aspecto, tendo levado ao incremento de suas habilidades de leitura (no sentido amplo), o que, consequentemente, influencia suas escolhas tradutórias.

Palavras-chave: Estudos da tradução. Linguística Competência tradutória. 


\begin{abstract}
This article aims at reporting on part of a study whose purpose was to investigate the development of in-training translators' bilingual subcompetence and meta-reflection (HURTADO ALBIR, 2005; PACTE, 2003; VASCONCELLOS; PAGANO, 2005; and others) on aspects concerning textuality/texture (HALLIDAY; MATTHIESSEN, 2014), in the Portuguese-English linguistic pair. The reported on part deals solely with the aspect relative to the relationship between texts and context. The research, oriented by SFL and translation studies, was developed via a pedagogical intervention and carried out with BA students in English and Translation at State University of Ceará. The corpus consisted of the answers given to questions in five pedagogical activities and the comments provided in initial and final interviews. The results pertaining to Activity 1 - about the texts-context relationship -, and the comments made in the final interview demonstrated an increase in the participants' level of bilingual subcompetence and in the level of their meta-reflexive capacity as for the aforementioned aspect, having led to an increment in their skills at reading (in a broad sense), which, consequently, influences their translation choices.
\end{abstract}

Keywords: Translation studies. Systemic-Functional Linguistics. Translation competence.

\title{
Introdução
}

Os avanços tecnológicos têm contribuído para uma maior interação entre os povos em várias áreas (conhecimentos, negócios, turismo etc.), o que tem levado ao aumento crescente da demanda por tradução de conteúdos em diferentes línguas. Esse cenário requer profissionais preparados para lidar com os contextos situacionais multilíngues, pois, independentemente das ferramentas ofertadas pelas tecnologias modernas que facilitam a tarefa tradutória e o contato frequente entre os falantes de diferentes línguas, ainda há dificuldades quanto à tradução de determinados textos em decorrência da possibilidade de haver alteração no conteúdo experiencial e na mensagem do texto-fonte (PAGANO, 2012).

Tais dificuldades ocorrem tanto por restrições ou interferências da estrutura da língua alvo quanto pela necessidade de adaptação do texto-alvo ao novo contexto cultural e situacional (VASCONCELLOS, 1997). Essa necessidade está relacionada à reconstrução do gênero textual de modo que seu propósito comunicativo frente ao público-fonte se mantenha o mesmo frente ao público-alvo, o que torna necessário levar em conta as diferenças culturais na construção do diálogo intercultural e o papel da língua em cada situação social reconstruída via texto traduzido.

Tendo em vista essa problemática - que envolve a crescente demanda por tradução, o enfrentamento de dificuldades na atividade tradutória e, por conseguinte, a necessidade de aprimoramento das 
V. 10 (esp)

8-28

ago.

2020

habilidades do tradutor em formação -, realizamos uma pesquisa ampla por meio de uma intervenção pedagógica voltada para tradutores em formação do Curso de Letras Inglês/Tradução do Centro de Humanidades da Universidade Estadual do Ceará (VIEIRA, 2018). A intervenção foi orientada pela Linguística Sistêmico-Funcional (doravante LSF) e pelos estudos da tradução e teve como objetivo investigar o desenvolvimento da subcompetência bilíngue e, em consequência, da metarreflexão ${ }^{1}$ desses tradutores, no par linguístico português-inglês, sobre aspectos relativos à textualidade (tessitura), a saber: relação textos-contexto, coesão estrutural (estrutura e progressão temáticas) e coesão não estrutural (gramatical e lexical) (HALLIDAY; MATTHIESSEN, 2014).

$\mathrm{Na}$ intervenção pedagógica conduzida durante a pesquisa maior (VIEIRA, 2018), abordamos os textos em relação de tradução como instâncias de um gênero e, portanto, exercendo função em um determinado contexto social ao realizarem processos sociossemióticos. Então, partindo da visão de texto inserido em seus contextos de cultura e de situação ${ }^{2}$ em que circulam, tratamos dos aspectos de textualidade já elencados, o que significa que consideramos os textos holisticamente: neles, são diferentes sistemas que atuam simultaneamente para a construção do tecido textual. No entanto, por limitação de espaço, relatamos, neste artigo, apenas os resultados concernentes ao aspecto contextual. Esse recorte se justifica por deverem ser as relações contextuais o ponto de partida da abordagem dos textos-fonte e alvo, visto que são elas que balizam as escolhas sistêmicas feitas no processo de construção textual pelo autor inicial e o tradutor, respectivamente.

A pesquisa, em sua inteireza, é relevante pela importância dos conhecimentos sobre questões que influenciam as escolhas que constroem o tecido textual durante a atividade tradutória e, ainda, pela escassez de estudos de intervenção pedagógica desenvolvidos com tradutores em formação na perspectiva da LSF. As pesquisas encontradas que se apoiaram na interface LSF/Estudos da Tradução se diferenciam pelo fato de esta ter explorado o ambiente de sala de aula a fim de tratar, explicitamente, dos aspectos textuais mencionados, focando na atividade tradutória. Vasconcellos (1997), bem como Figueredo e Pagano (2009), estudaram, comparativamente, a organização temática de textos literários fonte e

\footnotetext{
${ }^{1}$ Esses termos serão discutidos na subseção 'Algumas considerações sobre os estudos da tradução'.

2 Esses termos serão discutidos na subseção 'Algumas considerações sobre a Linguística Sistêmico-Funcional'.
} 
alvo. Braga, Martins e Pagano (2006) e Pagano (2012) são estudos voltados para o tradutor em formação e para os textos por eles produzidos, sem, porém, ter havido nenhum tipo de intervenção pedagógica. Braga (2007) e Kim (2010), embora tenham explorado o ambiente de sala de aula, não trataram dos mesmos aspectos abordados em Vieira (2018).

Contudo, esta pesquisa seguiu recomendações genéricas de alguns desses pesquisadores (KIM, 2010; VASCONCELLOS, 1997; entre outros) na direção de que há a necessidade de instrução linguística para ajudar o tradutor em formação a fazer escolhas de forma consciente (metarreflexão). Assim, houve contribuição para o preenchimento da principal lacuna deixada pelos estudos supracitados: a carência de estudos de intervenção pedagógica voltados para trabalhar habilidades linguísticas de tradutores em formação.

Este artigo consta de cinco seções, incluindo esta seção introdutória. A segunda seção trata dos referenciais teóricos; a terceira, do percurso metodológico; a quarta, da apresentação e discussão dos resultados do recorte ora apresentado; e a quinta, das considerações finais.

\section{Referenciais teóricos}

Tratamos, a seguir, dos pressupostos teóricos que nortearam a pesquisa aqui relatada, conforme o recorte estabelecido para este artigo. Em duas subseções, faremos considerações sobre a Linguística Sistêmico-Funcional e sobre os estudos da tradução.

Algumas considerações sobre a Linguística Sistêmico-Funcional

A LSF concebe a língua como uma semiose social, ou seja, como um conjunto de recursos em potencial com os quais construímos significados em textos orientados para desempenhar funções em contextos sociais. Ao conceber a língua como um potencial de recursos de significados, formas e sons-letras à disposição do usuário, a LSF enfatiza o eixo paradigmático da língua. Além disso, trata da organização linguística em torno de dimensões: instanciação, estratificação e metafunção (HALLIDAY; MATTHIESSEN, 2014). Dessa forma, é possível abordar os textos como sobreposições de tipos diferentes de significados e formas, sendo a compreensão desse aspecto relevante para as atividades de leitura, de produção textual e de tradução (VIEIRA; PRAXEDES FILHO, 2015). 
10 (esp)

8-28

ago.

2020

No que se refere à instanciação, a língua pode ser espectada, simultaneamente, das perspectivas do sistema e do texto, sendo o sistema linguístico o potencial da língua inserido na cultura, o qual é 'instanciado' na forma de texto. Há uma relação intrínseca entre sistema e texto, de forma que a instanciação é concebida como um contínuo em cujos polos aparecem o potencial (sistema) e a instância (texto), havendo entre eles padrões intermediários ou subpotenciais: os gêneros. Portanto, para a construção de textos destinados a desempenhar diversas funções na sociedade como instâncias de um gênero, os usuários fazem escolhas partindo do potencial disponível na sua cultura, significando, assim, que "a língua opera em contexto"3 (HALLIDAY; MATTHIESSEN, 2014, p. 32).

Contudo, ainda para Halliday e Matthiessen (2014), é apenas uma pequena parte da cultura - uma situação social -, que direciona as escolhas e é nela, então, que os significados são produzidos e negociados entre os usuários da língua em forma de texto. Decorre que, como a língua, o contexto também pode ser escrutinado de dois pontos de vista, que são igualmente polos do mesmo contínuo: partese da cultura de uma comunidade, onde está o sistema/potencial linguístico, e chega-se à situação local, onde está o texto. Então, o contexto de cultura é o contexto amplo e abrangedor, confundindo-se com a própria sociedade, enquanto o contexto de situação é específico e imediato ou uma instância da cultura, existindo, entre esses polos, uma área intermediária ou subcultura ou tipos de situação, onde estão os gêneros. Logo, conclui-se que o contexto de situação guia a construção do texto, que, por sua vez, instancia o gênero adequado a dado tipo de situação, do qual o contexto de situação é uma instância.

Depreende-se daí que é indispensável definir-se o contexto de situação, o que foi feito por meio destas variáveis: campo, relações e modo do discurso. O campo se refere à natureza do processo sociossemiótico, ou melhor, à atividade social em andamento, ao objetivo comunicativo e ao assunto tratado. As relações têm a ver com os participantes envolvidos no campo, seus papéis discursivos, suas relações de poder e de afeto e a durabilidade dessas relações. O modo do discurso diz respeito ao papel que o texto desempenha para viabilizar a atividade social do campo: o papel da língua, se constitutivo ou ancilar, o canal, se fônico ou gráfico, o meio, se oral ou escrito, o modo retórico, se informativo, didático ou outros (HALLIDAY,

$3[\ldots]$ language operates in context. 
1989; HALLIDAY; MATHIESSEN, 2014). Partindo-se da descrição dessas variáveis, pode-se prever os padrões lexicogramaticais de um texto. Por outro lado, analisando-se os padrões lexicogramaticais do texto, pode-se reconstruir seu contexto de situação (HALLIDAY, 1989). Portanto, compreender essa inter-relação é importante nas atividades de leitura, de produção textual e de tradução, uma vez que, da relação texto-contexto, resultam as diferenças e similaridades entre os textos.

Dentro de dado contexto de situação, Halliday e Mathiessen (2014) distinguem os processos sociossemióticos da variável campo como atividades de natureza social (as que realizam algo, sendo de fazer (of doing)) e de natureza social e semiótica (as que constroem significados, sendo de significar (of meaning)). Esta distinção está em consonância com o que Halliday (1978) denomina de categorias de primeira ordem (atividades em que o papel da língua não é constitutivo, mas ancilar) e de segunda ordem (atividades em que o papel da língua é constitutivo) dentro do contexto situacional. A figura ilustrativa desses processos em Halliday e Mathiessen (2014, p. 37) apresenta dois níveis de delicadeza. No primeiro, há oito atividades que, por sua vez, se subdividem em outros tipos no segundo nível. São elas4: expor (explicar, categorizar), reportar (inventariar, divulgar fatos, pesquisar), recriar (narrar, encenar), compartilhar (compartilhar experiências, compartilhar valores), fazer (controlar, colaborar), habilitar (instruir, regular), recomendar (aconselhar, promover) e explorar (resenhar, argumentar). Das oito atividades primárias, somente a atividade de fazer é classificada como de primeira ordem (social), enquanto as outras sete são classificadas como atividades de segunda ordem ou semióticas (de significar). Atentar para o tipo de atividade que um gênero realiza poderá contribuir para escolhas mais adequadas na construção de textos que o instanciam.

Sobre as dimensões estratificação e metafunção, a segunda é parte da primeira, visto que as metafunções ou funções universais da linguagem verbal compõem um dos estratos. Na perspectiva da estratificação, Halliday e Matthiessen (2014) postulam que a língua é um sistema semiótico complexo, organizado em estratos extra e

\footnotetext{
${ }^{4}$ As atividades destacadas em negrito encontram-se no primeiro nível de delicadeza e as que aparecem entre parênteses encontram-se no segundo nível (HALLIDAY; MATHIESSEN, 2014, p. 37).
} 
10 (esp)

8-28

ago.

2020

intralinguísticos que se relacionam pelo princípio da realização: enquanto os primeiros dizem respeito aos contextos de cultura e de situação, os outros referem-se à semântica, onde se encontram as metafunções, à lexicogramática e fonologia-fonética / grafologiagrafética. Assim, os significados no estrato semântico realizam as variáveis definidoras do estrato acima, o do contexto de situação, e são realizados pelas formas no estrato lexicogramatical, o qual, por sua vez, é realizado fonológica ou grafologicamente.

É de três grandes áreas de significados que se constitui a semântica e elas se confundem com as metafunções5: ideacional (experiencial e lógica), interpessoal (negociação e avaliatividade) e textual (mensagem e informação). O componente experiencial da metafunção ideacional possibilita a representação subjetiva das experiências humanas cotidianas, realiza a variável 'campo do discurso' do contexto de situação e é realizada pelo sistema lexicogramatical de transitividade. Seu componente lógico viabiliza a organização das experiências representadas em complexos experienciais por meio dos sistemas lexicogramaticais de relações tácticas (parataxe e hipotaxe) e de relações lógico-semânticas (expansão de uma oração por outra e projeção de uma oração por outra). O componente negociação da metafunção interpessoal permite a troca (interação), entre os participantes da atividade social em curso, de informações e de bens e serviços, realiza a variável 'relações do discurso' do contexto de situação e é realizado pelo sistema lexicogramatical de modo. Seu componente avaliatividade enseja a expressão de juízos de valor e posicionamentos, o que é realizado pelo sistema lexicogramatical de modalidade e outros recursos avaliativos. A metafunção textual, que realiza a variável modo do discurso do contexto de situação, torna possível a organização da mensagem e da informação nas orações e o estabelecimento de conexões entre as partes de um texto, exercendo o papel de viabilizar também a organização dos significados ideacionais e interpessoais, o que leva à construção de um texto coeso e coerente. Enquanto o componente mensagem é realizado pela estrutura temática (sistema lexicogramatical de tema), o componente informação é realizado pela estrutura da informação.

\footnotetext{
${ }^{5}$ A realização lexicogramatical das três metafunções se dá, simultaneamente, na ordem da oração.
} 
Algumas considerações sobre os estudos da tradução

Tendo em vista as diversas perspectivas dos estudos tradutórios, a pesquisa ora relatada fundamenta-se em considerações de autores cujos trabalhos se baseiam numa perspectiva descritiva e/ou linguístico-funcionalista da tradução (HALLIDAY, 1992; MATTHIESSEN, 2001; VASCONCELLOS; PAGANO, 2005; entre outros). Para Halliday (1992), a atividade tradutória "não é apenas criação de significados; ela é uma criação de significados guiada"' (HALLIDAY, 1992, p. 15) (grifo do autor) pelas escolhas feitas pelo autor do texto-fonte. Nessa mesma perspectiva, Matthiessen (2001, p. 64) postula que a '"tradução' não é um reflexo passivo do texto-fonte; é um ato criativo de reconstrução dos significados do texto-fonte como significados no 'texto-alvo' "' 7 . Tratase de uma atividade de natureza multilíngue e interdisciplinar, que requer habilidades diversas e conhecimentos linguísticos e extralinguísticos (MUNDAY, 2008). Nesse sentido, Vasconcellos e Pagano (2005, p. 198) afirmam que a tradução de um texto-fonte é uma entre as possíveis retextualizações desse texto e que, ao tomar consciência desse fato, o tradutor em formação poderá "enxergar a tradução como uma atividade de construção de significados, acontecendo em uma configuração situacional diferente daquela da textualização inicial".

Considerando essas ideias, ao desenvolver o trabalho com tradutores em formação, abordamos a tradução nesta perspectiva: reconstrução/retextualização dos significados construídos no textofonte por meio de novas escolhas em outro sistema linguístico, tendo em vista o papel que o texto-alvo desempenha na cultura-alvo (HALLIDAY, 1992; VASCONCELLOS; PAGANO, 2005; entre outros). Dessa forma, com base na dimensão paradigmática/sistêmica de língua ou língua como potencial de recursos, o tradutor precisa entender o texto-alvo como uma entre as possíveis alternativas para a tradução do texto-fonte, o que lhe permite escolher, dentre os recursos à disposição, aquilo que é mais provável na cultura-alvo (HALLIDAY, 1992). Além disso, faz-se necessário refletir sobre as implicações das escolhas feitas.

Os estudos sobre o desenvolvimento da competência tradutória a concebem como "um conhecimento especializado, integrado por um conjunto de conhecimentos e habilidades, que singulariza o tradutor

\footnotetext{
$\overline{6}[\ldots]$ it is not just creation of meaning; it is guided creation of meaning.

7 [...] "translation" is not a passive reflection of the original; it is a creative act of reconstruing the meanings of the original as meanings in the "target".
} 
10 (esp)

8-28

ago.

2020

e o diferencia de outros falantes bilíngues não tradutores" (HURTADO ALBIR, 2005, p. 19), capacitando-o para desempenhar sua atividade profissional de forma consciente. Conforme o modelo holístico PACTE ${ }^{8}$ (2003), essa competência abrange cinco subcompetências (bilíngue, extralinguística, estratégica, instrumental e de conhecimentos sobre a tradução) e componentes psicofisiológicos (memória, percepção, criatividade, entre outros).

Embora saibamos que as subcompetências funcionam de forma integrada durante o ato de traduzir, não teria sido possível dar conta de todas em um único projeto de pesquisa, o que nos fez focar em somente uma delas: a subcompetência bilíngue. Ela, para Hurtado Albir (2005), consiste de conhecimentos operacionais pragmáticos, sociolinguísticos, textuais e lexicogramaticais -, sobre ambas as línguas. Do ponto de vista dos conhecimentos textuais, a pesquisadora destaca alguns, tais como os relativos às relações contextuais, a gêneros textuais, à coesão e coerência. Na intervenção pedagógica, se considerada como um todo, foram abordados, com o fim de investigarmos o desenvolvimento desta subcompetência, esses conteúdos sob o viés teórico da LSF; no entanto, associamos, às relações contextuais, os processos sociossemióticos.

Foi nosso interesse também investigar se, de algum incremento da subcompetência bilíngue, decorreria alguma elevação da capacidade de metarreflexão dos tradutores em formação. Essa capacidade, no contexto da nossa pesquisa, diz respeito ao processo de elaboração de pensamento reflexivo sobre a tarefa tradutória, permitindo um monitoramento mais eficiente do processo de tradução, no sentido de que o tradutor precisa compreender os problemas tradutórios encontrados e tomar decisões conscientes para resolvê-los (ALVES, 2005).

\section{Percurso metodológico}

Em Vieira (2018)9 , a intervenção pedagógica foi conduzida durante o semestre letivo 2016.2 no âmbito da disciplina 'Tópicos em tradução de textos escritos' do Curso de Letras Inglês/Tradução do $\mathrm{CH}$-UECE. Os dados que compuseram o corpus foram gerados por

\footnotetext{
${ }^{8} \mathrm{O}$ grupo de pesquisa PACTE (Process in the Acquisition of Translation Competence and Evaluation), fundado em 1997 por tradutores e professores que trabalham com a formação de tradutores na Universidade Autônoma de Barcelona, investiga a aquisição de competência em tradução.

${ }^{9}$ Pesquisa aprovada conforme Parecer 1874766 do CEP-UECE.
} 
quatro dos alunos matriculados na disciplina ${ }^{10}$ e coletados por meio de atividades pedagógicas e de relatos, em entrevistas (no início e final da intervenção), sobre a experiência pedagógica. Foi adotada uma abordagem descritiva desses dados, os quais foram vistos como produto e processo tradutórios.

A intervenção foi orientada pela abordagem pedagógica baseada em gêneros da LSF ou Escola de Sydney 'Ler para Aprender' (MARTIN; ROSE, 2007; ROSE; MARTIN, 2012; entre outros), com algumas adaptações. Essa metodologia proporcionou aos participantes uma oportunidade de aprendizagem via ensino teórico-prático, visando incrementar seus conhecimentos - em português e inglês -, sobre os aspectos de textualidade/tessitura listados na seção introdutória, fomentar a conscientização sobre as escolhas feitas, quanto aos mesmos aspectos, pelos autores dos textos-fonte e suas próprias escolhas feitas na construção dos textos-alvo e ampliar seu domínio de conhecimento sobre as práticas do seu contexto social em relação a textos escritos. O Quadro 1 sumariza a metodologia adotada.

Quadro 1 - Estratégias pedagógicas e sua descrição

\begin{tabular}{|c|c|}
\hline Etapas & Descrição \\
\hline $\begin{array}{l}\text { (1) Preparação } \\
\text { para Leitura } \\
\text { (Fase: orientação) }\end{array}$ & $\begin{array}{l}\text { Etapa realizada em grupo sobre o reconhecimento do gênero e } \\
\text { da estrutura genérica dos textos-fonte e alvo, das variáveis do } \\
\text { contexto de situação social em que circularam e dos processos } \\
\text { sociossemióticos que realizam. }\end{array}$ \\
\hline $\begin{array}{l}\text { (2) Leitura } \\
\text { Detalhada/ } \\
\text { Preparação para a } \\
\text { Retextualização } \\
\text { (Fase: orientação) }\end{array}$ & $\begin{array}{l}\text { Etapa realizada tanto em grupo como individualmente. Incluiu a } \\
\text { leitura dos textos-fonte e análise dos elementos que constroem } \\
\text { sua tessitura no âmbito das orações, dos complexos oracionais, } \\
\text { dos parágrafos e dos textos como um todo. Os elementos dos } \\
\text { sistemas de coesão estrutural - Temas tópicos/ideacionais, } \\
\text { interpessoais e textuais + suas realizações e a progressão } \\
\text { temática -, e coesão não estrutural - gramatical e lexical -, } \\
\text { foram discutidos de forma imbricada, pois ambos os sistemas } \\
\text { contribuem para a formação do tecido textual. }\end{array}$ \\
\hline $\begin{array}{l}\text { (3) Retextualização } \\
\text { (Fase: redação) }\end{array}$ & $\begin{array}{l}\text { Etapa realizada individualmente, incluindo a tradução e a } \\
\text { revisão de textos instanciadores dos gêneros analisados. }\end{array}$ \\
\hline $\begin{array}{l}\text { (4) Revisão / } \\
\text { Consolidação da } \\
\text { atividade } \\
\text { (Fase: revisão) }\end{array}$ & $\begin{array}{l}\text { Etapa realizada em grupo por meio da discussão sobre as } \\
\text { escolhas feitas nas traduções e da troca de experiências sobre a } \\
\text { atividade tradutória. }\end{array}$ \\
\hline
\end{tabular}

Os aspectos de textualidade/tessitura, reapresentados nas duas primeiras etapas no Quadro 1, foram estudados por meio de cinco atividades pedagógicas, as quais foram elaboradas a partir de materiais 
v. 10 (esp)

8-28

ago.

2020

autênticos impressos (panfletos e folders bilíngues) que circularam no Brasil durante a Copa do Mundo de 2014. Na primeira atividade (A1), por intermédio de análise macrolinguística, foi explorada a noção de contexto e sua relação com os textos; na segunda (A2), via análise microlinguística, tratou-se do conteúdo relativo aos recursos do sistema de coesão não estrutural; na terceira (A3), foi estudado, de um ponto de vista igualmente microlinguístico, o conteúdo a ver com o sistema de coesão estrutural ou sistema de tema (a estrutura e a progressão temáticas); na quarta (A4), continuou-se a discussão sobre o sistema de tema, mas de uma perspectiva macrolinguística: Macrotema e Hipertemas $^{12}$; e a quinta atividade (A5) foi dedicada a um exercício de tradução tendo em vista a aplicação dos conteúdos discutidos.

Em virtude do recorte escolhido para este artigo, anunciado na seção introdutória, tratamos exclusivamente da Atividade 1 na seção subsequente. Portanto, a consecução do objetivo posto na introdução diz respeito somente a essa atividade.

\section{Apresentação e discussão de resultados}

Antes de apresentarmos os resultados da aplicação da A1, descrevemos a atividade propriamente dita. Uma vez tendo os resultados sido mostrados e discutidos, incluímos, ainda, alguns relatos feitos pelos participantes, na entrevista final, sobre a intervenção.

\section{Atividade 1: Descrição e resultados}

A princípio, os participantes foram convidados a folhear vários dos materiais autênticos que circularam no Brasil, em diversos contextos, durante a Copa do Mundo de 2014. Depois, deveriam escolher alguns deles, lê-los e tecer comentários, na etapa de Preparação para a Leitura, sobre suas características contextuais. Seus comentários focaram apenas em alguns traços do campo do discurso: o assunto tratado e alguns aspectos visuais que apontam para o evento, não tendo atentado para nenhum dos traços das variáveis relações e modo do discurso do contexto de situação.

\footnotetext{
${ }^{12}$ Com os conceitos de Hipertema e Macrotema, Martin (1992) amplia a noção de Tema para parágrafos e textos. Os Hipertemas (sentenças-tópico) apresentam a ideia geral de um parágrafo (o ponto de partida para interpretação da (hiper)mensagem de cada parágrafo), os Macrotemas (títulos de capítulos, livros e outros ou parágrafos introdutórios de um capítulo) predizem a sucessão de Hipertemas nos textos e o Tema funciona como o ponto de partida para a interpretação da mensagem no cotexto oracional.
} 
Após esses comentários iniciais, houve instrução sobre os contextos de cultura e de situação e suas influências nas escolhas feitas nos textos. Na sequência, foi apresentado um formulário-guia com as variáveis definidoras do contexto de situação e seus respectivos traços. Os Quadros 2 e 3 apresentam, respectivamente, o formulário e os textos analisados.

Quadro 2 - Atividade 1: formulário-guia

\begin{tabular}{|c|c|c|}
\hline \multicolumn{2}{|c|}{ ATIVIDADE: 1} & Aluno(s): \\
\hline \multicolumn{3}{|c|}{$\begin{array}{l}\text { Questão } 1 \text { - Identifique os traços que definem as variáveis do contexto de situação } \\
\text { em cada texto. }\end{array}$} \\
\hline \multirow[b]{4}{*}{ 茴 } & VARIÁVEIS & TRAÇOS \\
\hline & $\begin{array}{l}\text { Campo do discurso } \\
\text { (tipo de atividade) }\end{array}$ & $\begin{array}{l}\text { Atividade social ou Processo sociossemiótico } \\
\text { Objetivo comunicativo: } \\
\text { Assunto: }\end{array}$ \\
\hline & $\begin{array}{l}\text { Relações do discurso } \\
\text { (relações sociais } \\
\text { acontecendo } \\
\text { na atividade social) }\end{array}$ & $\begin{array}{l}\text { Participantes } \\
\text { Papéis } \\
\text { Relação social: ( ) temporária ( ) permanente } \\
\text { Status da relação: ( ) simétrica ( ) assimétrica } \\
\text { Distância social: ( ) máxima ( ) mínima }\end{array}$ \\
\hline & $\begin{array}{l}\text { Modo do discurso } \\
\text { (papel desempenhado } \\
\text { pela língua na } \\
\text { atividade social) }\end{array}$ & $\begin{array}{l}\text { Papel da língua: ( ) constitutivo ( ) ancilar } \\
\text { Meio: ( ) oral ( ) escrito } \\
\text { Modo retórico: }\end{array}$ \\
\hline \multicolumn{3}{|c|}{ Outras considerações: } \\
\hline \multicolumn{3}{|c|}{$\begin{array}{l}\text { Questão } 2 \text { - Compare os traços que definem as variáveis do contexto de situação } \\
\text { dos textos analisados e aponte semelhanças e diferenças entre essas variáveis que } \\
\text { podem ter influenciado nas escolhas realizadas para a construção/reconstrução dos } \\
\text { significados desses textos. }\end{array}$} \\
\hline
\end{tabular}

Quadro 3 - Textos utilizados na Atividade 1

Fontes: Panfletos do Banco do Brasil, DECON-CE e Ministério Público do Trabalho. 
v. 10 (esp)

8-28

ago.

2020

Após a apresentação do formulário-guia, os participantes \begin{tabular}{|l|l|}
\hline \multicolumn{2}{|c|}{ TEXTOS PARA ANÁLISE } \\
\hline Texto 1 (Fonte: Folder do Banco do Brasil) & Traduçăo do texto 1
\end{tabular}

O Banco do Brasil torce para que a sua permanência seja a mais agradável possivel. Para isso, wocể tem à sua dispasiçă 5 mil agéncias em todo o pais e 63 mil caixas eletrönicos. Em Fortaleza sła 36 agencias e diversos caixas eletrónicos situados em locais de fícil acesso para atender clientes e turistas nacionais e internacionais.

Prepare a tordida e aproveite.

Texto 2 (Fonte: Folder 'Justiga para o Consumidor Turista Agors' - DECON-CE).

ACESSIBILIDADE

Os estabelecimentos camerciais, ben como shopping centers, äreas privadas de lazer, estádios, ginúsios e estabelecimentos congâneres deveröo estar devidamente aptos para receber pessoes com necessidades especiais, sem que seja necessária a intervençäo de terceiros, garantindo o direito de ir e vir dos consumidores.

Os consumidores que, por qualquer motivo, sentirem $s e$ prejudicados, poderb́o realzar denúnciss aos óngisos de Proteçäo e Defesa do Consumidar, apontando o local e a imegularidade constatado, pars que sejam adotadas as providénciss cabiveis.

Texto 3 (Fonte: Parfleto sobre o Estatuto da Criança e do Adolescente, publicado pelo Ministério Público do Trabalho)

QUEM FAZ PROGRAMA COM CRLANCA ASSISTE À VIDA DA PRIST̃O.

EXPLORAÇÃO SEXUAL. DE CRTANCAS E ADOLFSCFNTFS NAO E BRINCADEIRA, E CRIME.

Banco of Brasil hopes that your stay in Brazil is as pleasant as possible. For this, you have at your disposal 5.000 branches across the country and 63.000 ATMs. In Fortaleza, there are 36 branches and several ATMs in easily accessible locations to service clients and national and international tourists.

Prepare to cheer, and have a great time!

Traducto do texto 2 (Fonte: Folder'Justice now for the tourlst consumer - DECON-CE.

ACCESSIBILITY

Businesses, as well as shopoing malls, private leisure areas, stadiums, gymnasiums and similar establishments must be duly prepared to receive people with special needs, without third party interventions, thus guaranteeing consumers' right to come and go,

Coneumers, whe for any reason foel disodvantaged, can report it to Consumer Protection and Deferse agencies, pointing out the plsces and the verfied irregularky, so that apprepriate action is taken.

\section{Tradução do texto 3}

OMLD SEX TOURISM: ONE-WAY TIOKET TO JAR.

SEXUNL EXPLOITATION OF OHILDREN OR TEENS IS NOT CHILD'S PLAY, IT'S A CRIME

CRIME HOTLINE: 100 POLICLA RODOVIARIA FEDERAL: 191

releram os textos para depreender os traços das variáveis do contexto de situação dos três textos, preenchendo, para cada um, o quadro síntese no formulário. Por fim compararam os traços a partir dos quadros preenchidos, buscando identificar as similaridades e diferenças entre os textos, bem como as características de sua linguagem. No Quadro 4, estão as respostas dos quatro participantes para a primeira questão dessa atividade ${ }^{13}$.

Quadro 4 - Respostas dos participantes relativas à Questão 1 da A1

\begin{tabular}{|c|c|c|c|c|}
\hline Variáveis & Traços & Texto 1 & Texto 2 & Texto 3 \\
\hline
\end{tabular}

${ }^{13}$ As informações que estão entre colchetes são intervenções nossas. 


\begin{tabular}{|c|c|c|c|c|c|}
\hline \multirow{11}{*}{ 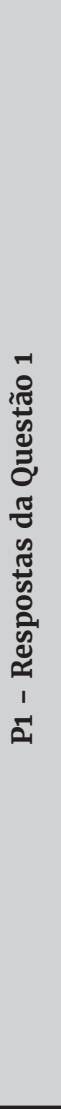 } & \multirow{3}{*}{ હ̈ } & $\begin{array}{l}\text { Atividade } \\
\text { social/processo } \\
\text { sociossemiótico: }\end{array}$ & $\begin{array}{l}\text { informar e divulgar } \\
\text { a imagem do } \\
\text { banco, propaganda, } \\
\text { recomendar. }\end{array}$ & $\begin{array}{l}\text { conscientizar sobre } \\
\text { direitos e deveres, } \\
\text { habilitar. }\end{array}$ & $\begin{array}{l}\text { advertir, regular } \\
\text { conduta. }\end{array}$ \\
\hline & & Objetivo: & $\begin{array}{l}\text { prestar serviço e } \\
\text { promover o banco }\end{array}$ & $\begin{array}{l}\text { instrumentalizar } \\
\text { alguém a fazer algo. }\end{array}$ & $\begin{array}{l}\text { advertir ao público } \\
\text { sobre a existência } \\
\text { da lei. }\end{array}$ \\
\hline & & Assunto: & $\begin{array}{l}\text { pontos de venda, rede } \\
\text { de atendimento. }\end{array}$ & acessibilidade & $\begin{array}{l}\text { crime de exploração } \\
\text { de crianças/ } \\
\text { adolescentes }\end{array}$ \\
\hline & \multirow{5}{*}{ 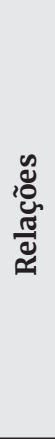 } & Participantes & $\begin{array}{l}\text { instituição bancária, } \\
\text { clientes e possíveis } \\
\text { clientes. }\end{array}$ & $\begin{array}{l}\text { DECON, } \\
\text { estabelecimento e } \\
\text { consumidores }\end{array}$ & $\begin{array}{l}\text { órgão regulador e } \\
\text { público em geral }\end{array}$ \\
\hline & & Papéis: & $\begin{array}{l}\text { prestador de serviços e } \\
\text { clientes }\end{array}$ & $\begin{array}{l}\text { prestadores e } \\
\text { tomadores de } \\
\text { serviços }\end{array}$ & $\begin{array}{l}\text { vítimas, } \\
\text { colaboradores e } \\
\text { possíveis infratores }\end{array}$ \\
\hline & & Relação social: & temporária & permanente & permanente \\
\hline & & Status da relação: & assimétrica & assimétrica & assimétrica \\
\hline & & Distância social: & mínima & máxima & máxima \\
\hline & \multirow{3}{*}{ 울 } & Papel da língua: & constitutivo & constitutivo & constitutivo \\
\hline & & Meio: & escrito & escrito & escrito \\
\hline & & Modo retórico & persuasivo & $\begin{array}{l}\text { normativo/didático e } \\
\text { informativo }\end{array}$ & injuntivo/didático \\
\hline \multirow{11}{*}{ 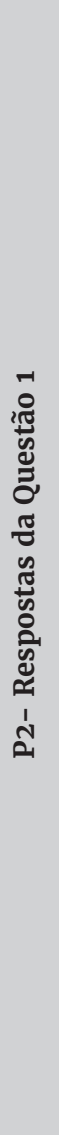 } & \multirow{3}{*}{ 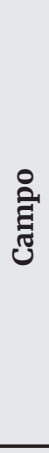 } & $\begin{array}{l}\text { Atividade } \\
\text { social/processo } \\
\text { sociossemiótico: }\end{array}$ & $\begin{array}{l}\text { propaganda, } \\
\text { recomendar }\end{array}$ & habilitar & advertir/habilitar \\
\hline & & Objetivo: & $\begin{array}{l}\text { informar os clientes } \\
\text { da presença e } \\
\text { prestatividade do } \\
\text { banco }\end{array}$ & $\begin{array}{l}\text { conscientizar os } \\
\text { clientes de seus } \\
\text { direitos e deveres. }\end{array}$ & $\begin{array}{l}\text { instruir o público } \\
\text { em geral. }\end{array}$ \\
\hline & & Assunto: & $\begin{array}{l}\text { disponibilidade do } \\
\text { banco para com o } \\
\text { cliente. }\end{array}$ & acessibilidade & $\begin{array}{l}\text { crime de exploração } \\
\text { sexual de menores. }\end{array}$ \\
\hline & \multirow{5}{*}{ 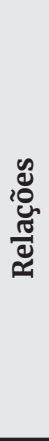 } & Participantes: & $\begin{array}{l}\text { instituição bancária, } \\
\text { clientes e possíveis } \\
\text { clientes. }\end{array}$ & $\begin{array}{l}\text { estabelecimentos, } \\
\text { órgão regulador e } \\
\text { consumidores }\end{array}$ & $\begin{array}{l}\text { órgãos reguladores } \\
\text { e público em geral }\end{array}$ \\
\hline & & Papéis: & $\begin{array}{l}\text { prestador de serviços e } \\
\text { usuário }\end{array}$ & $\begin{array}{l}\text { consumidores e } \\
\text { prestadores }\end{array}$ & $\begin{array}{l}\text { vítimas, possíveis } \\
\text { infratores e órgão } \\
\text { regulador. }\end{array}$ \\
\hline & & Relação social: & temporária & permanente & permanente \\
\hline & & Status da relação: & assimétrica & assimétrica & assimétrica \\
\hline & & Distância social: & mínima & máxima & máxima \\
\hline & \multirow{3}{*}{ 올 } & Papel da língua: & constitutivo & constitutivo & constitutivo \\
\hline & & Meio: & escrito & escrito & escrito \\
\hline & & Modo retórico & informativo & $\begin{array}{l}\text { explicativo e } \\
\text { principalmente } \\
\text { didático. }\end{array}$ & injuntivo, didático \\
\hline
\end{tabular}


v. 10 (esp)

8-28

ago.

2020

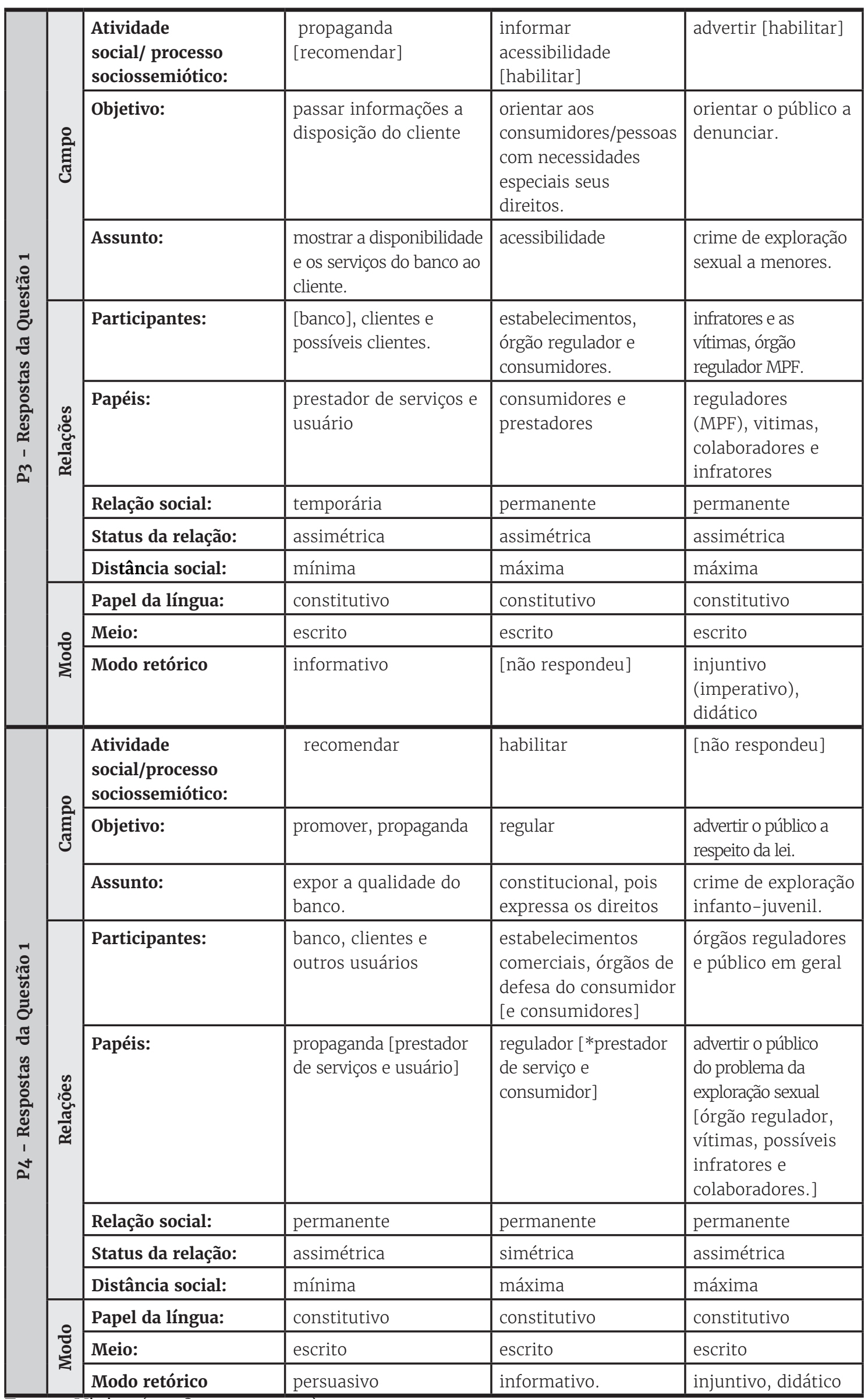

Fonte: Vieira (2018, p. 152-153). 
As respostas à Questão 2, que demandou a identificação das semelhanças e diferenças entre os textos pela comparação dos traços das variáveis dos respectivos contextos de situação, são as seguintes:

Todos os três tratam de aspectos diferentes e adotam tons diferentes em suas propagandas. O primeiro panfleto tem um tom mais convidativo e informativo, o segundo já tem um tom mais sério, pois trata de direitos de consumidores, e o terceiro é o mais sério dos três, pois é uma advertência e tem um tom extra sério. Quanto a tradução, o primeiro usou uma tradução idêntica à do texto-fonte, o segundo modificou alguns termos para algo mais conhecido culturalmente pelo leitor. No terceiro foi onde houve mais mudanças. Porém os três conseguiram ser bastante informativos e acertaram nas escolhas dos termos, tornando a mensagem mais receptiva ao leitor $(\mathbf{P 1})$.

Os textos têm diferentes construções, intuitos e modos retóricos. O primeiro tem como foco fazer propaganda do banco visando informar seus usuários e possíveis usuários, o segundo busca explicar aos clientes os seus direitos. O terceiro texto, com características injuntivas, tem como objetivo instruir o público em geral a denunciar casos como os citados. Todos mantém um status assimétrico com relação a seus leitores (P2).

(P3 não respondeu a Questão 2.)

O texto 1 dialoga com o leitor, apresentando uma voz imperativa (recomendação) e no processo tradutório mantem-se esses elementos, embora seja uma retextualização no texto de chegada. No texto 2, existe uma tentativa de informar o leitor sobre os seus direitos, então, o texto de chegada mantém o aspecto formal. Texto 3 é o texto mais direto, pois o anúncio é curto e tem por fim advertir (P4).

Na parte pós-instrução sobre a relação textos-contexto, os participantes foram motivados a fazer uma leitura detalhada dos significados construídos nos textos a partir da análise dos traços definidores das variáveis do contexto de situação. Suas respostas demostram que eles perceberam que, apesar de os textos serem semelhantes em alguns aspectos (meio, público-alvo e outros) e de terem circulado no mesmo evento, apresentam diferenças relevantes em termos dos assuntos tratados, objetivos comunicativos, processos sociossemióticos, das relações entre os participantes (autores e leitores em potencial) e dos modos retóricos. Por conseguinte, a análise dos traços das variáveis contextuais os levou à percepção de que são textos instanciadores de gêneros diferentes por cumprirem propósitos distintos, por meio de estruturas genéricas e realizações lexicogramaticais correspondentes, em tipos diferentes de situação. Se comparadas essas respostas aos 
10 (esp)

$8-28$

ago.

2020 comentários iniciais pré-instrução, nota-se que houve evolução para uma percepção mais abrangente da relação entre textos e seus contextos. Houve, portanto, incremento da subcompetência bilíngue.

Esse incremento foi crucial quanto ao sucesso da intervenção como um todo porque alguns estudos já haviam atestado que o conhecimento declarativo sobre os aspectos extralinguísticos dos textos é indispensável, na atividade tradutória, para a tomada de decisões fundamentadas e, portanto, mais conscientes diante de problemas tradutórios (ALVES, 2015; HALLIDAY, 1992; MAGALHÃES, 2015; entre outros). Tal relevância leva em conta que o texto traduzido é simultaneamente ligado ao texto-fonte e às pressuposições e condições do novo contexto (HALLIDAY, 1992), o que está em consonância com a ideia básica da LSF de que o texto e seu contexto de situação não podem ser vistos como entidades separadas (HALLIDAY, 1989). Assim, ao lidar com os textos (fonte e alvo), os tradutores precisam ter consciência dessa inter-relação, uma vez que, da combinação dos traços das variáveis contextuais, resultam diferenças e similaridades entre os textos (HALLIDAY; MATTHIESSEN, 2014) e essa consciência emergiu nos participantes. Logo, houve incremento também de seu nível de metarreflexão.

Como são os aspectos extralinguísticos dos textos que estão em foco, entendemos que a análise deles pode ser compreendida como parte da fase de orientação no processo tradutório. Essa análise inicial certamente repercute positivamente nas fases de produção e revisão textual.

\section{Sobre a entrevista final}

Na entrevista final, os participantes responderam perguntas sobre a intervenção pedagógica, seu envolvimento e suas dificuldades com as atividades, a aplicação dos conhecimentos adquiridos na atividade tradutória, bem como foram convidados a avaliar sua aprendizagem e a disciplina, além de fazer um comentário livre. Todos afirmaram que, durante a disciplina, tiveram dificuldades em relação ao conteúdo referente à LSF, mas que tinham conseguido apreender bastante dele a partir das discussões suscitadas por meio das atividades, esclarecer dúvidas e consolidar conhecimentos que entendiam ser úteis para as atividades de leitura, de produção textual e de tradução. Então, confirmaram, em seus relatos, que as atividades práticas possibilitaram - incluída, por óbvio, a A1 -, o desenvolvimento de habilidades para lidar com textos (fonte e alvo), para as quais a utilização do conteúdo aprendido foi indispensável (subcompetência bilíngue). 
P1 afirmou que passou a entender que pode "recriar um texto de uma forma diferente, mas que [faça] o mesmo sentido que o original [...]"; para tal, é imprescindível que o tradutor considere os aspectos contextuais. P3, referindo-se ao conteúdo da disciplina, disse: "[...] me fez ver de outro jeito também [ao] pegar um texto pra traduzir, me faz pensar, pensar no tipo [gênero], sobre o que eu poderia mudar, poderia usar outras formas". Tais afirmações estão em consonância com Vasconcellos e Pagano (2005, p. 198), pois defendem que uma das implicações de abordar a tradução como retextualização é o fato de liberar "o tradutor em formação da noção limitadora do texto de partida enquanto receptáculo de conteúdos estáveis e imutáveis [...]". P2 afirma em seus relatos que,

[ao] dividir o texto, separar as partes [estágios da estrutura genérica], encontrando as coisas [...] que definem o texto, fica bem mais fácil pra você entender o texto e pra que você consiga traduzir, [assim], escolher o rumo e como você vai usar e qual o alvo daquele texto o que você está vendendo no seu produto certamente [processo sociossemiótico] (P2).

Neste relato, P2 fala do seu percurso ao realizar as tarefas tradutórias, o que indica que ele/a passou a ter consciência de suas escolhas e que se apropriou dos pressupostos sobre os aspectos contextuais ensinados para uso na realização desse tipo de tarefa. Nesse sentido, P4 assevera que estudar e aplicar a teoria na tarefa tradutória ajuda a desenvolver competências e enfatiza a importância dos traços das variáveis do contexto de situação na construção do diálogo (textoleitor), tendo em vista a sua influência nos textos, uma vez que "a tradução vai além do texto".

Os comentários dos participantes nos licenciam a alegarmos que os conhecimentos relativos aos aspectos contextuais aplicados na prática da tradução elevaram a capacidade metarreflexiva deles, que passaram a ver esses conhecimentos como ferramentas para a análise dos textos. Essas ferramentas, por sua vez, os levaram a olhá-los sob uma ótica abrangente: passaram a identificar aspectos diversos, tendo focado não somente no campo, mas também nas relações e no modo do discurso.

Enfim, o estudo da relação textos-contexto sob o viés da LSF mostrou-se útil para a atividade de leitura - num sentido amplo -, o que, por conseguinte, impacta nas decisões do tradutor, ajudando-o a fazer escolhas mais conscientes. Dessa forma, trata-se de conhecimento que pode ser visto como ferramenta a ser utilizada como parte da fase de orientação do processo tradutório. 
10 (esp)

8-28

ago.

2020

\section{Considerações finais}

Os resultados da análise das respostas dadas pelos participantes às duas questões propostas na Atividade 1 e de seus relatos na entrevista final indicam que a intervenção pedagógica teórico-prática baseada na LSF foi eficaz para trabalhar o aspecto macrolinguístico contextual da textualidade/tessitura. A eficácia é constatada pelo fato de que houve incremento no nível da subcompetência bilíngue e metarreflexão dos participantes em relação a esse aspecto.

O incremento, por sua vez, é evidenciado pelo fato de que houve ampliação do foco de análise, pelos participantes, da relação textos-fonte e alvo com seus respectivos contextos situacionais. As habilidades desenvolvidas por eles contemplam, mais especificamente, a primeira fase ou fase de orientação - leitura/interpretação - do processo tradutório, a qual, certamente, influencia todas as decisões que o tradutor precisa tomar nas fases seguintes: produção/redação do texto-alvo e sua revisão.

Considerando que a análise e o reconhecimento das questões envolvidas na relação textos-contexto ampliam a capacidade de percepção dos significados inscritos e evocados nos textos, propomos que sejam consideradas. O conteúdo deve ser ensinado e aplicado a fim de que o conhecimento resultante possa ser usado como ferramenta facilitadora do processo tradutório, tornando-o mais eficiente. Vale lembrar que, além da instrução propriamente dita, outros fatores didáticos como a participação efetiva nas atividades propostas e a troca de experiências/compartilhamento de informações entre os alunos também contribuem para a formação do tradutor.

Tendo em vista que esta pesquisa foi desenvolvida em sala de aula e que, portanto, teve seus resultados validados empiricamente, ela poderá oferecer contribuições para a atividade tradutória, para a pedagogia da tradução e, por conseguinte, para a formação do tradutor. Para que a contribuição possa ser mais ampla, os resultados pertinentes aos outros aspectos relativos à textualidade/tessitura tratados na intervenção - coesão estrutural (estrutura e progressão temáticas) e coesão não estrutural (lexical e gramatical) -, serão apresentados em outras publicações.

\section{Referências}

ALVES, Fábio. Um modelo didático do processo tradutório: a integração de estratégias de tradução. 4. ed. In: PAGANO, Adriana Silvino; MAGALHÃES, Célia; ALVES, Fábio. Traduzir com autonomia: estratégias para o tradutor em formação. São Paulo: Contexto, 2015. p. 113-128. 
ALVES, Fábio. Ritmo Cognitivo, Meta-reflexão e experiência: parâmetros de análise processual no desempenho de tradutores novatos e experientes. In: PAGANO, Adriana Silvino; MAGALHÃES, Célia; ALVES, Fábio. (Orgs.). Competência em tradução: cognição e discurso. Belo Horizonte: Editora UFMG, 2005, p. 109-152.

BRAGA, Camila N. de Oliveira. Indagando o perfil de tradutores em formação: um estudo de caso. 2007. 143 p. Dissertação (Mestrado em Linguística Aplicada) - Faculdade de Letras da Universidade Federal de Minas Gerais, Belo Horizonte, 2007.

BRAGA, Camila N. de Oliveira.; MARTINS, Natália Teles; PAGANO, Adriana Silvino. An SFL approach to translation: thematic organization in translations produced by translation students. INTERNATIONAL SYSTEMIC FUNCTIONAL CONGRESS, 33. ed., 2006, São Paulo. Anais eletrônicos. São Paulo: PUC SP, 2006. Disponível em $<$ http://www4.pucsp.br/isfc/proceedings/list_of_all_articles.htm $>$. Acesso em: 23 jan. 2018. p. 1103-1114.

FIGUEREDO, Giacomo Patrocinio; PAGANO Adriana. Uma abordagem linguística do texto literário traduzido: aspectos da construção do romance They shoot horses, don't they? e sua tradução para o português, sob a perspectiva da organização temática. Graphos, João Pessoa, v. 11, p. 85-103, 2009.

HALLIDAY, Michael Alexander Kirkwood; MATTHIESSEN, Christian. Halliday's introduction to functional grammar. 4th ed. Ney York: Routledge, 2014.

HALLIDAY, Michael Alexander Kirkwood. Language theory and translation practice. Rivista internazionale di tecnica della traduzione, nr o (Pilot issui). Università di Trista, p. 15-25, 1992.

HALLIDAY, Michael A. Kirkwood. Part A. In: HALLIDAY, Michael A. Kirkwood; HASAN, Ruqaiya. Language, context, and text: aspects of language in a social semiotic perspective. 2. ed. Oxford: Oxford University Press, 1989. p. 1-49.

HALLIDAY, Michael A. Kirkwood. Language as social semiotic: the social interpretation of language and meaning. London: Edward Arnold (Publisher) Ltd., 1978.

HURTADO ALBIR, Amparo. A aquisição da competência tradutória: aspectos teóricos e didáticos. In: PAGANO, Adriana Silvino; MAGALHÃES, Célia; ALVES, Fábio. (Orgs.). Competência em tradução: cognição e discurso. Belo Horizonte: Editora UFMG, 2005. p. 19-57.

KIM, Mira. Translation error analysis: a Systemic Functional Grammar approach. In: COFFIN, Caroline; LILLIS, Theresa.; KIERAN, Hallaran (Eds). Applied Linguistics methods: a reader: Systemic Functional Linguistics, Critical Discourse Analysis and Ethnography. London: Routledge, 2010. p. 84-94.

MAGALHÃES, Célia. Estratégias de análise macrotextual: gênero, texto e contexto. In: PAGANO, Adriana; MAGALHÃES, Célia; ALVES, Fábio (Orgs.). Traduzir com autonomia: estratégias para o tradutor em formação. 4. ed. São Paulo: Contexto, 2015. p. 71-86.

MARTIN, James Robert; ROSE, David. Interacting with text: the role of dialogue in learning to read and write. Foreign Studies Journal, Beijing, v. 4, n. 5, p. 66-80, 2007. 
$10(\operatorname{esp})$

8-28

ago.

2020

MARTIN, James Robert. English text: system and structure. Philadelphia: John Benjamins Publishing Company, 1992.

MATTHIESSEN, Christian. The environments of translation. In: STEINER, Erich; YALLOP, Colin (Eds.). Exploring translation and multilingual text production, beyond content. New York: Mouton de Gruyer, 2001. p. 41-124.

MUNDAY, Jeremy Spencer. Introducing translation studies: theories and applications. 2. ed. London: Routledge, 2008.

PACTE. Building a translation competence model. In: ALVES, Fábio (Ed.). Triangulating translation: perspectives in process oriented research. Amsterdan: John Benjamins, 2003. p. 43-66.

PAGANO, Adriana Silvino. Modelagem sistêmico-funcional da tradução e da produção textual multilíngue. 2012. 233p. Tese (Concurso Público de Provas e Títulos para preenchimento de vaga para a classe de Professor Titular na área de Estudos Linguísticos) - Faculdade de Letras da Universidade Federal de Minas Gerais, Belo Horizonte, 2012.

PAGANO, Adriana Silvino. Organização temática e tradução. In: PAGANO, Adriana; MAGALHAES, Célia; ALVES, Fábio (Orgs.). Competência em tradução: cognição e discurso. Belo horizonte, UFMG, 2005. p. 247- 299.

PRAXEDES FILHO, Pedro Henrique Lima. In: ARAÚJO, Júlio. C.; BIASI, Bernardete. R.; DIEB, M. (Eds.). Seminários linguísticos: discurso, análise linguística, ensino e pesquisa. Mossoró: Editora da UERN, 2010. p. 305-325.

ROSE, David; MARTIN, James Robert. Learning to write, reading to learn: genre, knowledge and pedagogy in the Sydney School. Sheffield, United Kingdom: Equinox Publishing, 2012.

VASCONCELLOS, Maria Lúcia Barbosa de; PAGANO, Adriana Silvino. Explorando interfaces: Estudos da Tradução, Linguística Sistêmico-Funcional e Linguística de Corpus. In: ALVES, Fábio; MAGALHÃES, Célia, PAGANO, Adriana Silvino (Orgs.). Competência em tradução: cognição e discurso. Belo Horizonte, MG: Editora da UFMG, 2005. p. 177-208.

VASCONCELLOS, Maria Lúcia Barbosa de. Can the translator play with the system, too?: a study of thematic structure in some Portuguese translations. Cadernos de tradução, v. 1, n. 2, p. 149-187, 1997.

VIEIRA, Teresinha Penaforte. Estudo sobre a subcompetência bilíngue e a metarreflexão de tradutores em formação sobre questões de tessitura textual: uma intervenção pedagógica baseada na LSF. 2018. 275p. Tese (Doutorado em Linguística Aplicada) - Centro de Humanidades, Universidade Estadual do Ceará, Fortaleza, 2018.

VIEIRA, Teresinha Penaforte; PRAXEDES FILHO, Pedro Henrique Lima. Subcompetência bilíngue e metarreflexão: uma intervenção pedagógica com tradutores em formação sobre aspectos da tessitura textual via Linguística Sistêmico Funcional. Revista Veredas, PPG - linguística/UFJF, Juiz de Fora - MG, vol. 19, n. 2, p. 71-93, 2015. Disponivel em: http://www.ufjf.br/revistaveredas/ files/2015/04/SUM\%C3\%81RIO-19-021.pdf. Acesso em: 10 jan. 2017. 